\title{
Breaking bad news to people with learning disabilities and dementia
}

1. Irene Tuffrey-Wijne (PhD, RN) (Corresponding author), Associate Professor St George's University of London \& Kingston University, Faculty of Health, Social Care and Education, $2^{\text {nd }}$ Floor Grosvenor Wing, Cranmer Terrace, London SW17 ORE. Email: I.Tuffrey-Wijne@sgul.kingston.ac.uk

2. Karen Watchman (PhD, MSc, BA), Alzheimer Scotland Senior Lecturer in Dementia

Alzheimer Scotland Centre for Policy and Practice, Institute of Healthcare, Policy \& Practice, University of the West of Scotland, Caird Building, Hamilton, ML3 0JB, Scotland. Email: Karen.Watchman@uws.ac.uk

\begin{abstract}
People with learning disabilities are now enjoying a longer life expectancy than ever before as a result of enhanced medical and social interventions and improved quality of life. As a consequence of this we now know that some people with a learning disability, particularly individuals with Down syndrome, are susceptible to dementia at a significantly younger age. Currently there is limited guidance on how to talk about dementia to someone with a learning disability. Yet until information is shared about dementia, we are unable to position people with a learning disability as an authority on their condition. The new model presented in this article suggests a way of supporting staff and family to have enabling conversations about dementia with people with a learning disability that centre around their current situation and level of understanding and capacity.
\end{abstract}

\section{KEY WORDS}

Intellectual disability/learning disability, Dementia, Breaking bad news, Disclosure, Information, Communication

This is an Author's Accepted Manuscript, this is not the Version of Record, which can be found here: 
AUTHOR COPY

Accepted for publication in Learning Disability Practice on 03/07/2015

\section{Introduction}

Breaking bad news to someone with learning disabilities is never easy. Add dementia to the mix, and the challenge may seem insurmountable. In-depth studies of the experiences of people with learning disabilities who had cancer and those with a dementia showed that breaking bad news and giving explanations about the illness was a major concern for all those involved (Tuffrey-Wijne et al. 2010; Watchman, 2014). Staff and families worry about how much people with learning disabilities understand and how much explanation they should be given. People with learning disabilities continue to be protected from all kinds of bad news (McEnhill 2008; Bernal \& Tuffrey-Wijne 2008) and difficulties remain in sharing a diagnosis of dementia even if everyone agrees that it should be discussed with the ill person. There are concerns that the person won't be able to understand, or that the news will be too upsetting. Sometimes the family opposes disclosure, or it may simply be that nobody feels they have the skills to break bad news. However, there is evidence that people with learning disabilities cope better with difficult situations, such as illness, loss and bereavement, if they understand them (Blackman 2003; Tuffrey-Wijne et al. 2013). Bad news usually means that someone's life is changing in some way, and people need help to understand these changes in their lives.

In this article, we aim to provide some guidance around helping someone with learning disabilities understand that they have dementia and the implications of this diagnosis. We start from the premise that people with learning disabilities must receive such support, provided that it is given with due consideration for individual needs and preferences - which could include the need or preference not to know. We will explain new guidelines for breaking bad news to people with learning disabilities (developed by the first author, see Box 1) and demonstrate how these guidelines can be adapted for use with people with dementia, using the real-life example of Alice (described by the second author; Alice is a pseudonym). 
AUTHOR COPY

Accepted for publication in Learning Disability Practice on 03/07/2015

\section{Attitudes to breaking bad news}

Half a century ago, doctors didn't usually tell patients that they had a serious illness such as cancer (Oken 1961). Attitudes in Western societies started to change in the 1970s, towards a now overwhelming consensus among health care professionals and patients that it is best to be open and honest about the diagnosis (Novack et al. 1971; Seale 1991; Innes \& Payne 2009). It is widely understood that the way bad news is communicated can have a significant impact on the way patients and families adjust to serious illness. It has been found that dementia patients in the general population don't experience a catastrophic emotional reaction when they are told their diagnosis; rather, they experience relief that there is an explanation for their symptoms and that a treatment plan can be developed (Carpenter et al. 2008). There is no reason to believe that this would be any different for people with learning disabilities (Watchman 2013).

These early developments originated in the field of oncology. The change in attitude towards disclosure of a dementia diagnosis is more recent, but since the start of the 21st century there has been a shift towards thinking that early disclosure is beneficial to the patient, and is the starting point for medical and social interventions (Werner et al. 2013). National dementia strategies across all UK countries state that everyone should be given their diagnosis (Department of Health 2009; Department of Health Social Services and Public Safety 2011; Scottish Government 2013). The National Institute for Health and Clinical Excellence (NICE) guidelines (2006) state that a diagnosis of dementia should only be withheld from someone in exceptional circumstances. Instead, discussion should take place early after diagnosis to enable the person to be involved with future planning before their capacity and ability to communicate deteriorates.

\section{How to break bad news to people with learning disabilities}

An overview of the process of breaking bad news in relation to someone with learning disabilities and dementia is given in Figure 1. 


\section{AUTHOR COPY}

Accepted for publication in Learning Disability Practice on 03/07/2015

\section{Figure 1}

Breaking bad news to people with learning disabilities: an overview

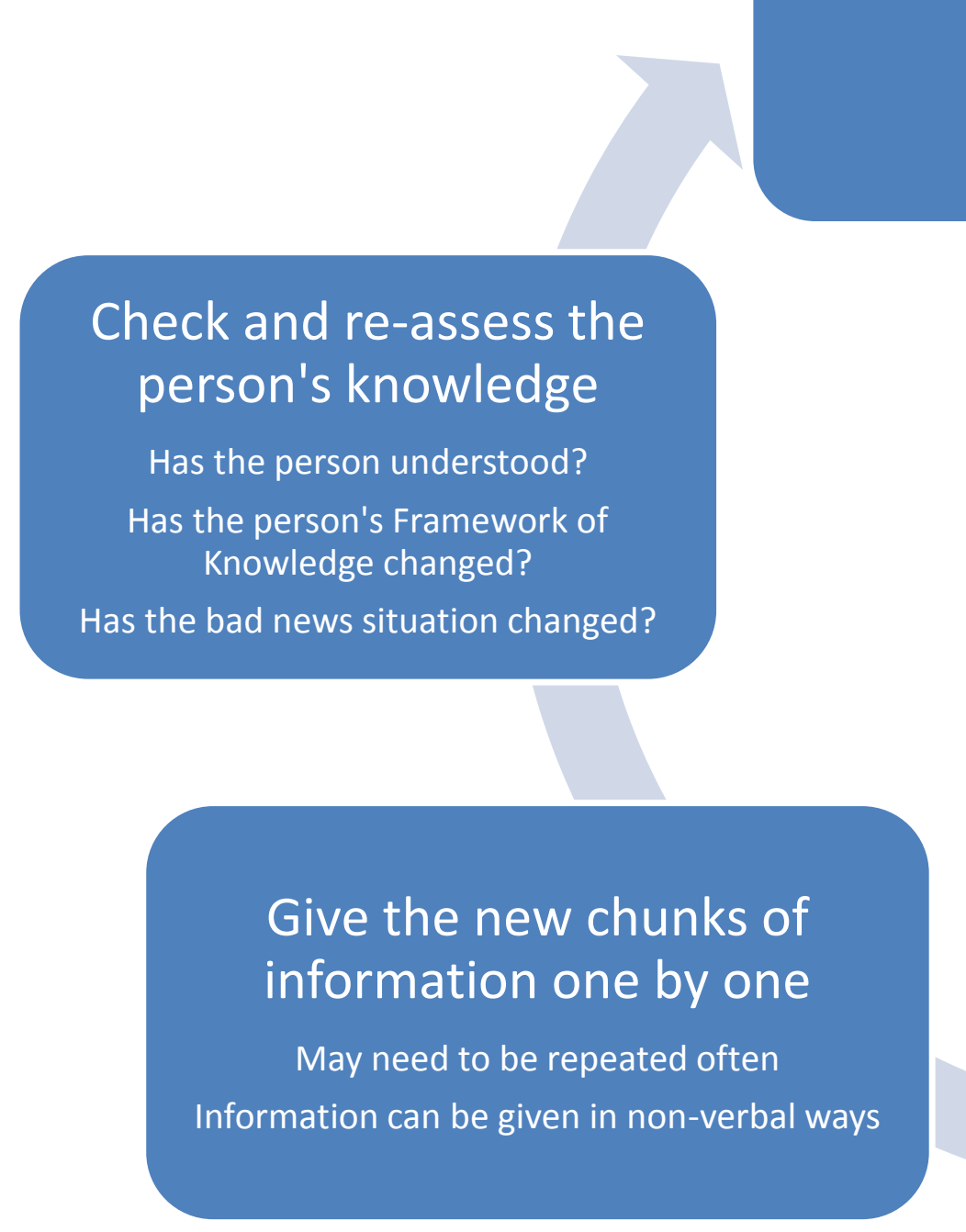

Build up a picture of the person's current"Framework of Knowledge"

Background knowledge

What is happenign right now

What will happen in the future
Check and re-assess the person's knowledge

Has the person understood? se person's Framework of Knowledge changed?

Has the bad news situation changed?
Give the new chunks of

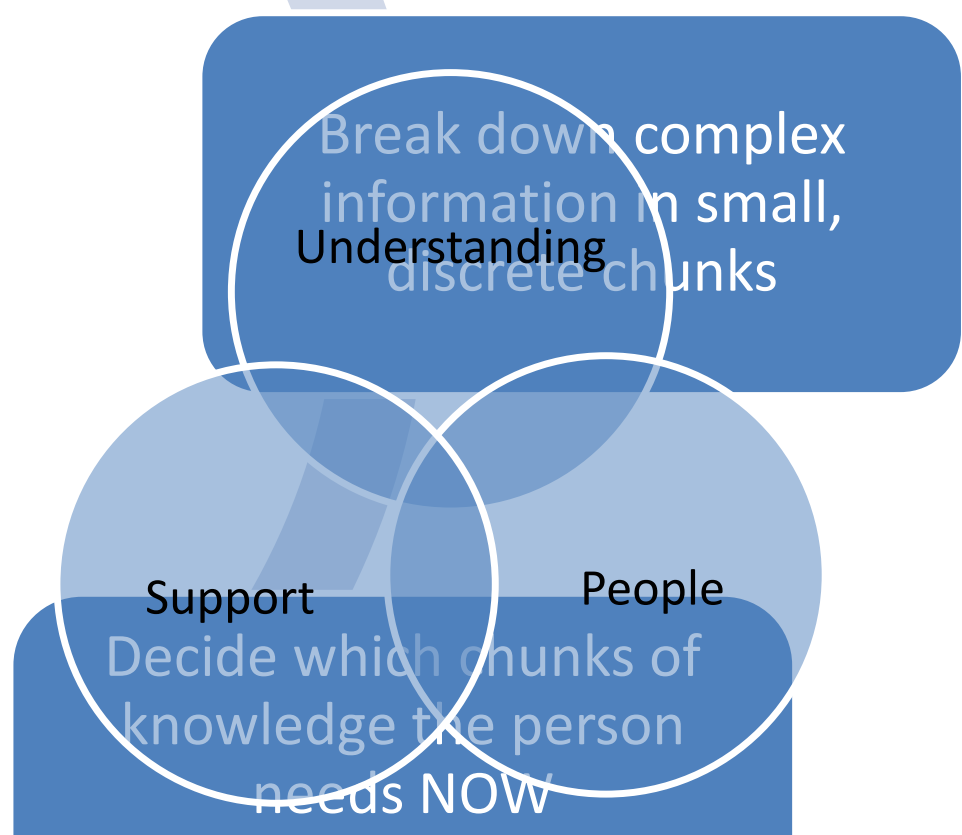

New information must make sense to the person (fit in with current Framework of Knowledge) 
AUTHOR COPY

Accepted for publication in Learning Disability Practice on 03/07/2015

\section{What is the bad news?}

The following may seem obvious and perhaps even unnecessary, but imagine a scenario where someone with learning disabilities has never heard of dementia and has a limited capacity for abstract thinking. Telling this person that he has dementia and will gradually lose his skills is unlikely to be experienced as 'bad news'. It may be that for this person, 'bad news' is being told that the swimming pool is closed or that there is no custard to go with the apple pie.

Bad news is "any news that drastically and negatively alters the patient's view of his or her future" (Buckman 1985) (p.1597). Someone's experience of news as 'bad' is therefore dependent on their concept of time and future, as well as their capacity for abstract thinking. You need to establish not only whether this is actually bad news for an individual, but also which aspects of the bad news they need to be helped to understand.

\section{What is the person's current 'framework of knowledge'?}

Any new information needs to make sense to the person: it needs to fit in with their current understanding and experience of life. In order to do so, we need to establish what someone's existing 'framework of knowledge' is, so that we can build on it. To do this, we will need to try and stand in the person's shoes. How do they see, experience and understand the world? Without a fairly detailed knowledge of someone's experience and current framework of knowledge, it will be difficult to know whether, and how, new information will be understood and processed.

It can be helpful to break down someone's current knowledge into chunks that fit into these three categories:

1. Background knowledge. This can include, for example: knowledge about how the world works; general knowledge about illness and death; memories; life experience; knowledge about how we and other people have been feeling in the past; concept of time. There may be many gaps on someone's background knowledge.

2. Knowledge about what is happening in the present. This includes both current 
events and current feelings. The knowledge framework of people with profound learning disabilities or advanced dementia may be limited to this; they may have little knowledge of the past or the concept of the future.

3. Knowledge about what will happen in the future. How much of the future someone understands will be influenced by their intellectual capacity, their capacity for abstract thinking and their concept of time.

Information about the person's framework of knowledge should be gathered from as many people as possible; the insights of families and carers are of particular importance. (See figure 2 for a simplified example of Alice's framework of knowledge).

\section{Break the information down into small chunks}

A seemingly simple statement ("You have dementia") is actually very complex. It can include:

- background knowledge, for example 'dementia is an illness of the brain'

- knowledge about the immediate implications on a day to day basis, for example. 'I can't find the toilet and it scares me'

- understanding of future changes, for example 'dementia gets worse, not better'

New information needs to be broken down into singular, distinct, small chunks of information. How small these chunks need to be depends on the individual.

\section{Decide which chunks of new information to add}

You then need to try and establish which of these chunks the person already possesses, which will make sense now, which may not make sense until later, and which are unlikely ever to be retained or make sense at all.

Having an understanding of someone's current framework of knowledge will help to decide which chunks of new information to add. It is only useful to explain to someone that they have dementia, if their 'background knowledge' includes an understanding or experience of dementia. You can then focus on the implication of the diagnosis for this person. But if someone cannot grasp the concept of a brain that can get ill, then there is no 


\section{AUTHOR COPY}

Accepted for publication in Learning Disability Practice on 03/07/2015

point trying to convey this information. You may need to simplify it to "You are not well" (sticking to information about the present moment) and "It is not your fault" (adding a small but important chunk of background knowledge about the nature of dementia). Indeed, if background or future chunks of knowledge are absent, it may be best to stick with information about the present moment. One way of doing this is by affirming (and not denying or glossing over) worrying things that are happening (e.g. "I can see you don't like going down the stairs; let me take your arm and we'll go together" - or, if the person's verbal understanding is limited, simply taking their arm in a calm and reassuring manner). This is particularly relevant for people with complex and profound learning disabilities, who often live life completely in the present moment, and find it hard to link previous experiences to current situations or to anticipate the future. Further important considerations include:

- Does the person like to think about what is going to happen tomorrow or next week, or do they live day to day?

- Denial of bad news is a valid and important coping mechanism; it is important to respect this.

- How well does the person cope with anticipation, change and uncertainty? Usually, people need enough support to understand the current changes in their life and benefit from being able to anticipate these changes in some way, but there are also people who find such anticipation too difficult. It makes them so anxious that they find it hard to cope; for example, they may be better off not knowing that they need to go to the dentist until the morning of the appointment.

- Always bear in mind the person's capacity to understand. The laws on mental capacity must be adhered to. People should be given the best possible chance of understanding, so it is important to consider what and who they need to help ensure the best possible communication, and how information can best be given.

\section{Give the new chunks of information one by one}

New knowledge (including an understanding of bad news) is not just gained through explanation and education, but also through experience and through reasoning ("My mum 


\section{AUTHOR COPY}

Accepted for publication in Learning Disability Practice on 03/07/2015

had dementia and went into a nursing home, therefore if I have dementia I will have to go into a nursing home"). For many people (including those without learning disabilities) 'experience' is a much more powerful way of gaining knowledge than 'explanation of facts'. It will help to have an insight into how the person usually processes new information: does he benefit from verbal explanations, pictures, experiences, lots of repetition? (see Box 2).

See the case study for an example of how Alice associates hospital with a negative experience as her mother died in one: 'I didn't see her, she went to hospital and didn't come back'. Alice's concern is not about having dementia, as this has no meaning for her. However, it will be exacerbated by activities that happen as a result of it (such as hospital appointments) because of her experience when her mum died. Alice may benefit from only being told on the morning of the appointment, or it may be possible to arrange home visits or appointments in a clinical setting out with the local hospital.

Staff and carers often worry that they are not "the right person" to impart or consolidate new information. However, everyone with a significant involvement in the life of the person should be included and involved sharing the diagnosis. They will all have a role to play in helping to understand the changes.

\section{Check and re-assess}

It is important to assess on an on-going basis how much someone has understood, how their framework of knowledge has changed, and how their actual situation has changed. This will help to establish what other new knowledge needs to be added or explained.

\section{Support for everyone}

Everybody's support needs should be considered, not just the needs of the person with learning disabilities. Family and care workers may be particularly affected by the bad news. Helping someone with learning disabilities understand and cope with bad news is difficult, and in order to do it well, everyone needs support, including emotional, practical and spiritual support. 
AUTHOR COPY

Accepted for publication in Learning Disability Practice on 03/07/2015

\section{How does dementia affect someone's framework of knowledge?}

Usually, someone's framework of knowledge grows over time. However, when people have dementia, their framework is shrinking and their chunks of knowledge are gradually shifting. The boundaries between background knowledge and 'what is happening right now' may become blurred. Knowledge that consists of memories can begin to disappear, especially those memories that more recent. Background knowledge that consists of the person's world view, or an understanding of how the world works, may also change. Values and behaviour learnt in recent decades may gradually disappear, leaving the person with an understanding that is related to a much earlier time in their life. Additionally, knowledge that is expressed through life skills may also disintegrate over time. Knowledge and understanding of what is going to happen in the future, whether that is next year or tomorrow or in five minutes' time, will also start to disappear. Over time, the ability of someone with dementia to understand or even experience what is happening right now will be reduced to an ever-decreasing window.

Assessing what and how much someone with dementia should be told about their diagnosis needs a constant re-evaluation of their framework of knowledge. If someone's current experience and understanding is that their father is alive and present today, it is not helpful to insist on repeated explanations that their father is dead. Such explanations will result in unnecessary distress: it does not fit with the person's current experience and it is a devastating chunk of bad news to be processed again and again.

During the earlier stages of dementia, people are likely to notice that things are changing for them. Without an explanation of the changes that are being experiences this can cause unnecessary distress that can be alleviated by explaining, in appropriate words or picture, that this is part of an illness. Family, peers or a partner, need help to understand this too. (See useful resources in Box 2).

An assessment of what someone with a learning disability and dementia can be helped to understand should include a consideration of future changes. The changes in someone's framework of knowledge mean that capacity to make decisions will gradually be lost along with the ability to understand implications for the future. Any involvement in decision making should therefore take place as early as possible, before such capacity is lost. 
AUTHOR COPY

Accepted for publication in Learning Disability Practice on 03/07/2015

\section{CASE STUDY: Alice}

Alice is 49 years old, she has Down's syndrome and has been diagnosed with dementia. Alice lives with her sister Claire and brother in law Jamie, an arrangement that was agreed with Alice and Claire's mother before her death three years earlier. Alice attends a day centre three days a week. She is becoming agitated and recently has started hitting friends and staff at the centre and crying for no obvious reason. At home she is becoming more confused and often sits quietly, whereas previously she was usually animated and sociable and attended dance classes twice a week.

Day centre staff alerted Claire to changes that they had observed in Alice over a number of months; she no longer engaged with activities that she had previously enjoyed. When Claire thought about it she realised that she had noticed subtle changes herself but had not realised the implications. In fact Alice had been showing symptoms of dementia for over a year before her family and staff realised that something was wrong and advice was sought from the community learning disability nurse. This led to further referrals and the process of making a diagnosis of dementia over a period of eight months. Claire and Jamie are unsure of what to say to Alice about her diagnosis, or even if they should say anything at all.

The first step is to find out about Alice's current framework of knowledge. Any new information will only make sense to Alice if it fits with this. We need to separate her understanding and experience of the following:

- background information about dementia and illness

- what she thinks is happening to her right now

- what she thinks will happen in the future

Figure 2 depicts what Alice's current framework of knowledge might look like. The next step is to decide which small, separate chunks of information can be simplified so that Alice can understand them more easily. Alice has no awareness of what it means to have dementia, so using the words 'dementia' or 'Alzheimer's disease' will not have meaning without further explanations. It is important to focus on the immediate implications on a day to day basis. 'I don't like going to the day centre, it scares me' and 'something is wrong with me' are examples of day to day issues. 'I am scared of hospitals' may become an issue as medical 


\section{AUTHOR COPY}

Accepted for publication in Learning Disability Practice on 03/07/2015

intervention increases. Discussion of future needs to focus on these issues in order to ensure that Alice's sense of wellbeing increases.

Figure 2: Alice's current framework of knowledge

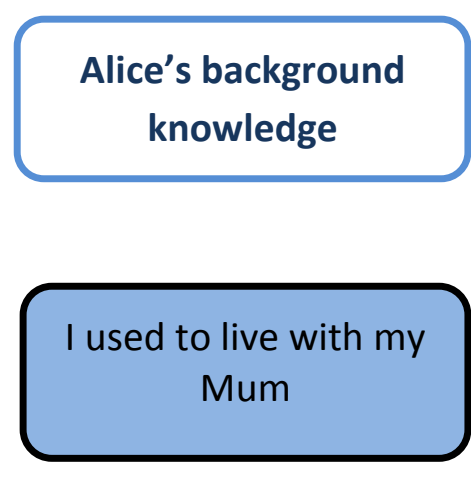

My mum got ill and then she died

I didn't see my mum before she died. She went into hospital and didn't come home.
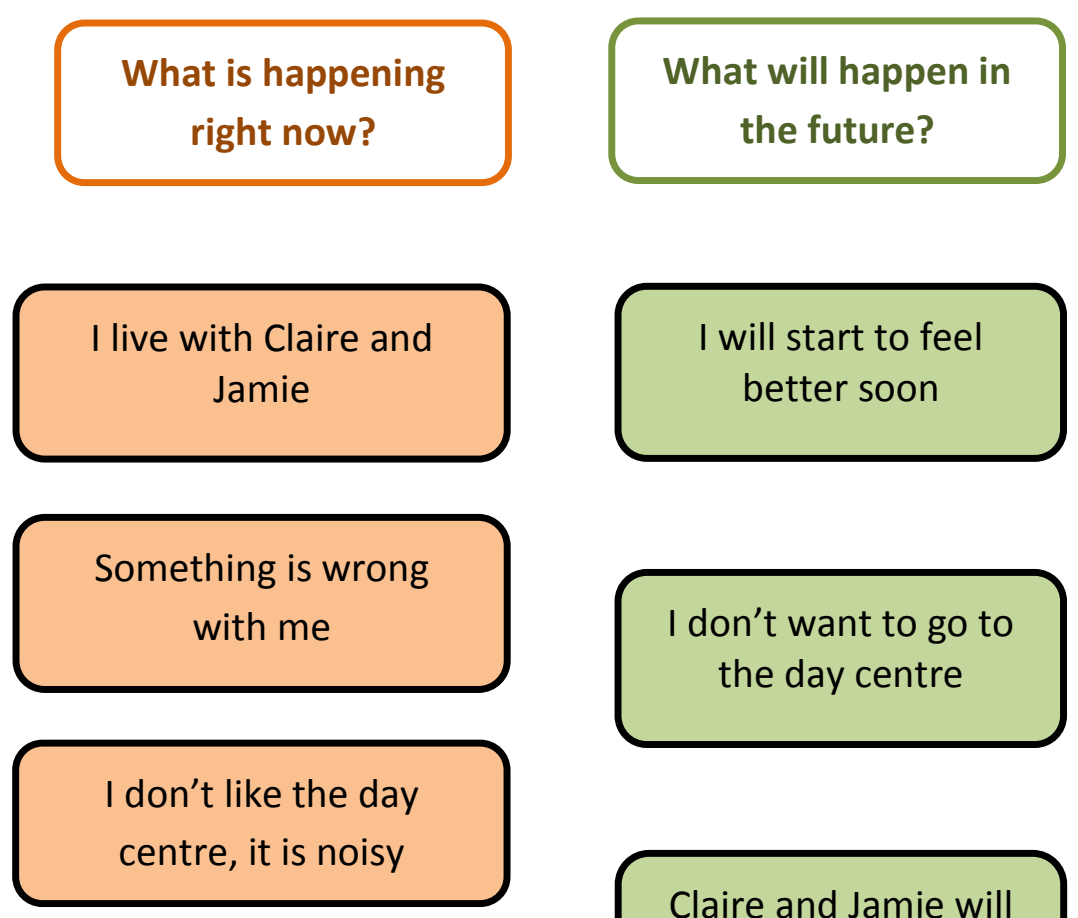

I don't know why I don't feel like dancing anymore, it makes me sad

I don't want to go to the day centre

Claire and Jamie will look after me

I am scared of hospitals 


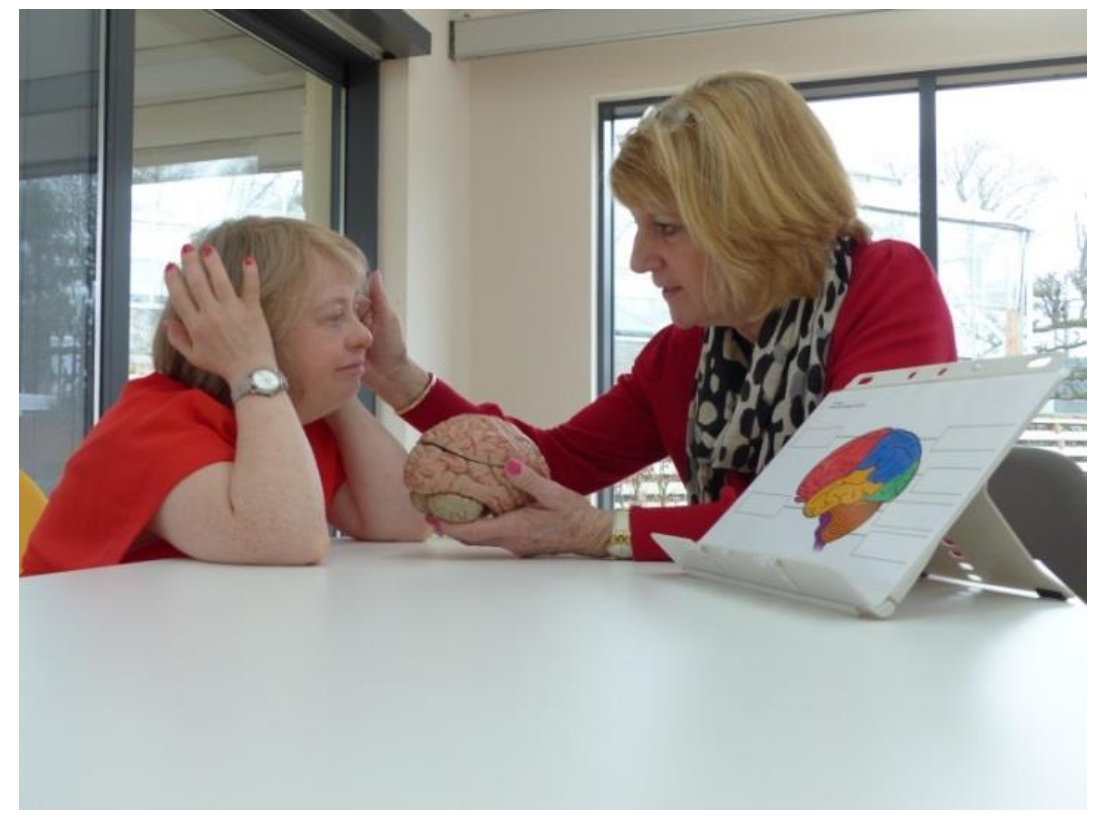

Alice is learning that she has an illness (posed by actors)

The third step is to give Alice new pieces of information one by one, that fit in with her current framework of knowledge. Whilst Alice's background knowledge is correct, she associates her mother being ill and hospital stays with her subsequent death, so discussion about this will need to be handled sensitively. Alice has indicated that she has concerns herself by asking 'what is wrong with me?'. At this stage, it will help Alice to understand that these changes and difficulties are caused by her illness, 'you are not well', although the word dementia should not be used without further explanation as it is not within her framework of knowledge. The focus can then be on what it means for her on a day to day basis. This will reassure her that the changes she is experiencing are not her fault and that family, friends and staff will help her. She may have her own ideas about what this help should be.

It will also be helpful to address some of Alice's perceptions about the future as there may be choices to be made about attending the day service. If she is able to think about relevant issues now, then you will have helped her to understand her future situation. This way Alice can be involved in her future care planning. It is important to include all those who provide support for Alice and for everyone to use the same words to describe her illness. For example, she may be able to arrive later and start earlier at the day centre which would avoid some of the busiest, noisiest times. Everyone can help Alice to build her 


\section{AUTHOR COPY}

Accepted for publication in Learning Disability Practice on 03/07/2015

framework of knowledge although what is 'current' for Alice will change as dementia progresses.

The fourth step is to keep checking with Alice whether she still understands what she has been told, whether she needs to understand more, or if something different is needed. Rather than Alice's knowledge and understanding growing, it will start shrinking. Those around her will need to re-write Alice's framework as often as is needed.

A particular feature of dementia is that older memories can become an experience of the present day. Alice's memory of her mother may become more prominent; she may forget her mother has died. If this happens, there is no need to put that piece of knowledge back into her past by reminding her that her mother is dead, as this doesn't fit in with her new framework of knowledge. Correcting her can cause unnecessary confusion and distress. Instead, you can affirm her experience, 'yes, your mum liked to go shopping didn't she?' or 'Ah, you're thinking of your mum, that's nice!' (depending on the context of the conversation) and then change the subject, 'perhaps Claire can help you chose your new shoes'; 'shall we make a cup of tea now?'. The most important thing is for Alice to feel safe and supported.

\section{Conclusion}

In this article, we have discussed the challenges around sharing a diagnosis of dementia with people with learning disabilities. Understanding how to support conversations about dementia is complicated by a lack of guidance on how to break bad news to people whose cognitive function is limited and will deteriorate further due to their dementia. We have explained new guidelines for breaking bad news to people with learning disabilities, and explored its use for individuals with dementia. In our case study, the use of the guidelines was helpful, but further evidence (both from practice and from research) is needed to refine them and to understand how they can best be used in practice. The authors welcome any feedback on this article and will be interested to hear practitioners' experiences. 


\section{AUTHOR COPY \\ Accepted for publication in Learning Disability Practice on 03/07/2015}

* Creative Commons Attribution - Non Commercial - No Derivatives 4.0 International Public Licence, reproduced with permission from Watchman, K. Tuffrey-Wijne, I. \& Quinn, S. (2015) Jenny's Diary: A resource to support conversations about dementia with people who have a learning disability (available summer 2015). London, Alzheimer's Society.

\section{References}

Bernal, J. \& Tuffrey-Wijne, I., 2008. Telling the truth - or not: disclosure and information for people with intellectual disabilities who have cancer. International Journal on Disability and Human Development, 7(4), pp.365-370.

Blackman, N., 2003. Loss and learning disability, London: Worth Publishing.

Buckman, R., 1985. Breaking bad news - why is it still so difficult? British Medical Journal, 6430, pp.1597-1599.

Carpenter, B. et al., 2008. Reaction to a dementia diagnosis in individuals with Alzheimer's disease and mild cognitive impairment. Journal of the American Geriatric Society, 56(3), pp.405-412.

Cresswell, A. \& Tuffrey-Wijne, I., 2008. The come back kid. British Journal of Learning Disabilities, 36(3), pp.152-156.

Department of Health, 2009. Living well with dementia: a national dementia strategy, London: The Stationery Office.

Department of Health Social Services and Public Safety, 2011. Improving dementia services in Northern Ireland: a regional strategy. Available at: http://www.dhsspsni.gov.uk/improving-dementia-services-innorthern-ireland-a-regional-strategy-november-2011.pdf [Accessed April 1, 2015].

Innes, S. \& Payne, S., 2009. Advanced cancer patients' prognostic information preferences: a review. Palliative Medicine, 23(1), pp.29-39.

Keightley, J. \& Mitchell, A., 2004. What factors influence mental health professionals when deciding whether or not to share a diagnosis of dementia with the person? Aging and Mental Health, 8(1), pp.13-20.

McEnhill, L.S., 2008. Breaking bad news of cancer to people with learning disabilities. British Journal of Learning Disabilities, 36(3), pp.157-164. Available at: http://doi.wiley.com/10.1111/j.14683156.2008.00517.x [Accessed September 17, 2013].

National Institute for Health and Clinical Excellence (NICE) (2006) Dementia: Supporting people with dementia and their carers in health and social care, clinical guideline 42 . Manchester, NICE.

Novack, D. et al., 1971. Changes in physicians' attitudes toward telling the cancer patient. Journal of the Americal Medical Association, 241(9), pp.897-900.

Oken, D., 1961. What to tell cancer patients: a study of medical attitudes. Journal of the American Medical Association, 175(13), pp.1120-1128.

Pucci, E. et al., 2003. Relatives' attitudes towards informing patients about the diagnosis of Alzheimer's disease. Journal of Medical Ethics, 29(1), pp.51-55. 


\section{AUTHOR COPY}

\section{Accepted for publication in Learning Disability Practice on 03/07/2015}

Scottish Government, 2013. Scotland's national dementia strategy 20113-2016. Available at: http://www.gov.scot/Topics/Health/Services/Mental-Health/Dementia/DementiaStrategy1316 [Accessed April 1, 2015].

Seale, C., 1991. Communication and awareness about death: a study of a random sample of dying people. Social Sciences and Medicine, 32(8), pp.943-952.

Tuffrey-Wijne, I. et al., 2013. Developing guidelines for disclosure or non-disclosure of bad news around lifelimiting illness and death to people with intellectual disabilities. Journal of Applied Research in Intellectual Disabilities, 26(3), pp.231-242.

Tuffrey-Wijne, I. et al., 2010. Exploring the lived experiences of people with learning disabilities who are dying of cancer. Nursing Times, 106(19), pp.15-18.

Watchman, K., 2013. At a crossroads in care: the experience of individuals with Down's syndrome and dementia. University of Edinburgh.

Watchman, K. (2014) Reducing marginalisation in people with a learning disability and dementia, Australian Journal of Dementia Care. 2(6), pp.31-34.

Watchman, K. Tuffrey-Wijne, I. \& Quinn, S. (2015) Jenny's Diary: A resource to support conversations about dementia with people who have a learning disability (available summer 2015). London, Alzheimer's Society.

Werner, P., Karnieli-Miller, O. \& Eidelman, S., 2013. Current knowledge and future directions about the disclosure of dementia: a systematic review of the first decade of the 21s century. Alzheimers dementia, 9(2), pp.74-88.

Woods, B. \& Pratt, R., 2005. Awareness in dementia: ethical and legal issues in relation to people with dementia. Aging and Mental Health, 9(5), pp.423-429. 
AUTHOR COPY

Accepted for publication in Learning Disability Practice on 03/07/2015

\section{BOX 1: Guidelines for breaking bad news to people with learning disabilities}

The guidelines described in this article are based on a model for breaking bad news developed by Irene Tuffrey-Wijne, following a programme of research in this area. Full details, including tools and examples, can be found on this website:

http://www.breakingbadnews.org/

There is also a comprehensive book on the guidelines: Tuffrey-Wijne, I (2012) How to break bad news to people with intellectual disabilities: a guide for carers and professionals.

London: Jessica Kingsley Publishers.

\section{BOX 2: Additional reading}

Watchman, K. Tuffrey-Wijne, I. \& Quinn, S. (2015) Jenny's Diary: A resource to support conversations about dementia with people who have a learning disability (in development). London, Alzheimer's Society.

Watchman, K. (Ed) (2014) Intellectual Disability and Dementia: Research into Practice. London. Jessica Kingsley.

Watchman, K., Kerr, D \& Wilkinson, H. (2010) Supporting Derek: a practice development guide to support staff working with people who have a learning disability and dementia. Joseph Rowntree Foundation/Pavilion Publishing https://www.pavpub.com/supporting-derek/

Foundation for People with Learning Disabilities - Peer support activities handbook http://learningdisabilities.org.uk/content/assets/pdf/publications/talkingtogether.pdf?view=Standard

Learning (intellectual) disability and dementia website: www.learningdisabilityanddementia.org 